\title{
Accelerated pubertal development in patients with shunted hydrocephalus
}

Tuija Löppönen, Anna-Liisa Saukkonen, Willy Serlo, Päivi Tapanainen, Aimo Ruokonen, Mikael Knip

\begin{abstract}
Objective-To evaluate pubertal development and peripheral concentrations of gonadotrophins and sex hormones in children with shunted hydrocephalus compared with healthy controls.

Study design-114 patients (52 females, 62 males) and 73 healthy controls (35 females, 38 males) aged 5 to 20 years were analysed for stage of puberty, age at menarche, testicular volume, basal serum follicle stimulating hormone (FSH), luteinising hormone (LH), sex hormone binding globulin (SHBG), testosterone and oestradiol concentrations, and free andro-
\end{abstract} gen index.

Results-Male gonadal and male and female pubic hair development occurred significantly earlier in the patients than in the controls. The mean age at menarche was significantly lower in the female patients than in their controls (11.7 $v 13.2$ years; $p<0.001$ ), and lower than it had been for their mothers ( $v$ 13.1 years; $p<0.001)$. Relative testicular volume was higher in the male patients than in their controls (1.2 standard deviation score (SDS) $v 0.2$ SDS; p < 0.001). The prepubertal patients had higher basal LH $(0.13$ U/1 $v 0.08 \mathrm{U} / 1 ; p<0.001)$ and SHBG (132.3 nmol/1 $v 109.1 \mathrm{nmol} / \mathrm{l} ; \mathrm{p}<0.01$ ) than the controls. Both the prepubertal and pubertal females had significantly higher basal FSH than their controls $(1.57$ U/l $v 1.03$ $U / 1 ; p<0.05$, and 4.0 U/1 $v 2.9$ U/1; $p<0.01$, respectively).

Conclusions-Hydrocephalic children experience accelerated pubertal maturation, reflected in a younger age at menarche in females and an increased testicular volume in males. This may be because of enhanced gonadotrophin secretion, possibly resulting from unphysiological variations in intracranial pressure.

(Arch Dis Child 1996;74:490-496)

Keywords: hydrocephalus, puberty, gonadotrophins.

Most previous reports on endocrine disorders in children with shunted hydrocephalus describe individual cases of sexual precocity. ${ }^{1-3}$ Close to $10 \%$ of the children with shunted hydrocephalus studied by Kaiser et al (8/90 patients) developed sexual precocity. ${ }^{4}$ Precocious puberty has especially been observed in patients with meningomyelocele, but Mayer and Landau found that 52 patients out of 79 with this disease had associated hydrocephalus ${ }^{5}$ and $6 \%$ of these had precocious puberty (3/52), raised basal oestradiol and testosterone, and raised peak luteinising hormone (LH) and follicle stimulating hormone (FSH) responses to gonadotrophin releasing hormone $(\mathrm{GnRH})$. The prevalence of cryptorchidism among boys with meningomyelocele was observed to be $15 \%$ (7/45). In another survey all 45 patients with meningomyelocele had hydrocephalus, ${ }^{6}$ and the various stages of puberty were reached earlier than expected, indicating that puberty advances more rapidly in children with this disease. Precocious puberty was observed in $4 \%$ of the patients $(2 / 45)$ and cryptorchidism in one quarter of the boys. The age at menarche varied from 9.4 to 11.9 years $(n=4)$.

Since most previous reports on precocious puberty in children with hydrocephalus concern mainly meningomyelocele patients, there is a lack of information on the average timetable of sexual maturation in hydrocephalic children and adolescents with an aetiology other than meningomyelocele. We report here on pubertal development, age at menarche, and gonadotrophin and sex hormone concentrations in 114 patients with shunted hydrocephalus in comparison with 73 healthy controls.

\section{Methods}

SUBJECTS

The initial series comprised 212 shunted hydrocephalic patients aged 5 to 20 years who had undergone their primary operation at the Department of Paediatrics, University Central Hospital, Oulu, Finland, during the 26 year period 1966 to 1991. Patients with tumours $(n=24)$ or achondroplasia $(n=3)$ were excluded, as were patients with an intelligence quotient (IQ) below $50(n=26)$, since factors other than the hydrocephalus itself may have
Abbreviations
$\mathrm{B}=$ breast
$\mathrm{BMI}=$ body mass index
CNS $=$ central nervous system
FAI = free androgen index
FSH $=$ follicle stimulating hormone
$\mathrm{G}=$ genitals
$\mathrm{GnRH}=$ gonadotrophin releasing hormone
$\mathrm{IQ}=$ intelligence quotient
$\mathrm{LH}=$ luteinising hormone
$\mathrm{PH}=$ pubic hair
SDS = standard deviation score
SHBG = sex hormone binding globulin
SLVS $=$ slit ventricle syndrome 
influenced their growth and pubertal development. Fourteen patients had moved to another university hospital district and 30 had died. One patient refused to participate. Thus the final population comprised 114 patients (52 females, 62 males), including 17 with spina bifida (11 females, six males) and 97 without (41 females, 56 males). Thirty eight children without spina bifida (15 females, 23 males) were prepubertal, while 59 (26 females, 33 males) were pubertal $(n=54)$ or postpubertal $(n=5)$. Six of the 17 subjects with spina bifida were prepubertal and 11 pubertal or postpubertal.

The clinical evaluation was carried out at the Department of Paediatrics, University Central Hospital, Oulu, Finland. Informed consent was obtained from the subjects or their parents or both. The research was conducted according to the Declaration of Helsinki. The mean age of the patients at the final evaluation was 11.8 years (range 5.0 to 19.9 years) and that of the controls 12.0 years (range 5.1 to 19.7 years). The median age of the hydrocephalic patients at the first operation had been 0.5 years (range 0.0 to 14.2 years), the females having been operated on earlier than the males (median 0.2 years (range 0.0 to 8.6 years) $v 0.7$ years (range $0.0-14.2$ years); $p<0.03$ ). The mean duration of the shunting period had been 10.0 years (range 1.3 to 19.8 years). Most of the shunts involved in the final evaluation were of the Hakim-Cordis type $(n=74)$, but OrbisSigma shunts had been used more often recently $(n=26)$. There were still some patients operated on earlier who had received a Pudenz shunt $(n=14)$. Most of the shunts were ventriculoperitoneal $(n=90)$ and a minority ventriculoatrial $(n=24)$. An antisiphon device had been installed in 46 patients. The median number of shunt revisions was two per patient (range 0 to 14).

The aetiology was assessed according to a modification of the classification proposed by Amacher and Wellington, excluding neoplastic tumours as a possible aetiological condition..$^{7-9}$ Magnetic resonance imaging was performed on a subgroup of 61 patients at the final evaluation and their aetiological diagnosis was based on these findings. ${ }^{10}$ The aetiology was congenital in 76 cases $(66.7 \%$ ), with the following subgroups: infantile obstructive hydrocephalus $(n=33 ; 28.9 \%)$; intracranial cerebrospinal cysts $(n=20 ; 17.5 \%)$; other intracranial anomalies $(n=6 ; 5.3 \%)$; and spina bifida $(n=17 ; 14.9 \%)$. Twenty eight patients $(24.6 \%)$ had acquired hydrocephalus, including $25(21.9 \%)$ with a perinatal aetiology (asphyxia or intracranial haemorrhage or both) and three $(2.6 \%)$ with an infectious aetiology. Ten patients (8.8\%) were included in the group of miscellaneous aetiology.

The control children were recruited among the appropriate age groups from neighbouring child welfare clinics and schools. They were invited to participate after thorough information to the child and the parents. One girl with diabetes and another 10.5 year old girl, who was diagnosed in the course of this investigation as having coeliac disease, were excluded, resulting in a final series of 73 controls ( 35 females, 38 males), of whom 32 (13 females, 19 males) were prepubertal and the remaining 41 (22 females, 19 males) pubertal $(n=36)$ or postpubertal $(n=5)$.

\section{PROCEDURES}

All the patients and controls were examined by one of us (TL). The anthropometric measurements were made three times and the mean value was calculated for subsequent use. Height was measured to the next succeeding $1.0 \mathrm{~mm}$ with a Harpenden wall mounted stadiometer and weight to an accuracy of $0.1 \mathrm{~kg}$ with an electronic scale. The relative height and the relative weight were assessed from Finnish growth charts. ${ }^{11}$ The body mass index (BMI) represents the ratio between weight $(\mathrm{kg})$ and height squared $\left(\mathrm{m}^{2}\right)$. The waist and the hip were measured to the next succeeding $1.0 \mathrm{~mm}$ with a metallic tape measure. ${ }^{12}$ The biceps, triceps, and subscapular skinfolds were measured to an accuracy of $0.1 \mathrm{~mm}$ with a Harpenden skinfold caliper (John Bull, British Indicators Ltd, St Albans, Herts, UK). ${ }^{13}$ Body density was calculated from the combined results of triceps and subscapular skinfold thickness according to Parizkova. ${ }^{14}$ The percentage of body fat was calculated by the method described by Keys and Brozek. ${ }^{15}$

The stage of puberty was assessed according to Tanner and Whitehouse. ${ }^{16}$ If there were no signs of puberty (G1PH1 or B1PH1), the subjects were classified as prepubertal. Subjects with full sexual maturation (G5PH5 or B5PH5) and adult bone age were classified as postpubertal. True precocious puberty was recorded in males if they reached stage 2 in genital development before the age of 9.5 years or stage 2 in pubic hair before 10.0 years and in females if they reached stage 2 in breast development before 8.0 years and stage 2 in pubic

Table 1 Anthropometric measurements in prepubertal and pubertal male patients with hydrocephalus and their controls; values are mean (95\% confidence interval)

\begin{tabular}{|c|c|c|c|c|c|c|}
\hline \multirow[b]{3}{*}{ Age (years) } & \multicolumn{3}{|l|}{ Prepubertal } & \multicolumn{3}{|l|}{ Pubertal } \\
\hline & Patients ( $n=26)$ & Controls $(n=19)$ & \multirow{2}{*}{$\begin{array}{l}p \\
0.30\end{array}$} & Patients ( $n=36)$ & Controls $(n=19)$ & \multirow{2}{*}{$\begin{array}{l}p \\
0.26\end{array}$} \\
\hline & $8.1 \quad(7.2$ to 8.9$)$ & 8.7 (7.8 to 9.7$)$ & & 14.7 (13.9 to 15.6$)$ & 15.4 (14.5 to 16.3$)$ & \\
\hline Height $(\mathrm{cm})$ & $124.2(119.1$ to 129.4$)$ & $133.0 \quad(127.4$ to 138.6$)$ & 0.02 & $165.2(160.5$ to 169.9$)$ & $172.6(166.9$ to 178.3$)$ & 0.04 \\
\hline Relative height (SDS) & $-0.81(-1.36$ to -0.27$)$ & $0.12(-0.32$ to 0.56$)$ & 0.01 & $0.13(-0.31$ to 0.57$)$ & $0.52(0.03$ to 1.01$)$ & 0.20 \\
\hline Weight (kg) & $27.1 \quad(23.2$ to 31.1$)$ & 29.1 (26.2 to 32.0$)$ & 0.29 & $56.9(51.7$ to 62.1$)$ & $59.2(53.4$ to 65.0$)$ & 0.55 \\
\hline Relative weight (\%) & 108.2 (100.8 to 115.7$)$ & $100.3(96.1$ to 104.5$)$ & 0.15 & $107.3(101.5$ to 113.1$)$ & 99.7 (92.9 to 106.5$)$ & 0.05 \\
\hline $\mathrm{BMI}\left(\mathrm{kg} / \mathrm{m}^{2}\right)$ & $17.2(15.9$ to 18.5$)$ & $16.3(15.6$ to 17.0$)$ & 0.68 & 20.5 (19.4 to 21.7$)$ & $19.8(18.5$ to 21.0$)$ & 0.47 \\
\hline Waist-hip ratio & $0.89(0.88$ to 0.91$)$ & $0.84(0.82$ to 0.86$)$ & 0.001 & $0.86(0.84$ to 0.88$)$ & $0.80(0.79$ to 0.82$)$ & 0.001 \\
\hline Body fat mass (\%) & 17.8 (15.8 to 19.8$)$ & $15.6(14.4$ to 16.9$)$ & 0.18 & 17.2 (15.0 to 19.3$)$ & $11.6(8.2$ to 15.0$)$ & 0.001 \\
\hline
\end{tabular}

SDS = standard deviation score. 
Table 2 Anthropometric measurements in prepubertal and pubertal female patients with hydrocephalus and their controls; values are mean (95\% confidence interval)

\begin{tabular}{|c|c|c|c|c|c|c|}
\hline \multirow{4}{*}{ Age (years) } & \multicolumn{3}{|l|}{ Prepubertal } & \multicolumn{3}{|l|}{ Pubertal } \\
\hline & Patients ( $n=18$ ) & Controls ( $n=13$ ) & \multirow{2}{*}{$\frac{p}{0.84}$} & Patients ( $n=34)$ & Controls $(n=22)$ & \multirow{2}{*}{$\frac{p}{0.51}$} \\
\hline & $7.1 \quad(6.2$ to 8.0$)$ & $7.1 \quad(6.1$ to 8.0$)$ & & 14.1 (13.1 to 15.2$)$ & 14.7 (13.3 to 16.1$)$ & \\
\hline & 118.6 (112.4 to 124.9$)$ & 124.7 (118.0 to 131.3$)$ & 0.17 & $152.6(147.5$ to 157.7$)$ & 160.2 (155.9 to 164.4$)$ & 0.02 \\
\hline Relative height (SDS) & $-0.74(-1.5$ to 0.0$)$ & $0.47(-0.1$ to 1.0$)$ & 0.01 & $-0.76(-1.66$ to 0.14$)$ & $0.41(-0.10$ to 0.92$)$ & 0.05 \\
\hline Weight (kg) & 23.1 (19.7 to 26.6$)$ & 24.6 (21.2 to 28.1$)$ & 0.41 & 55.3 (49.3 to 61.2$)$ & $49.3(45.0$ to 53.6$)$ & 0.32 \\
\hline Relative weight (\%) & $103.0(95.9$ to 110.1$)$ & 98.5 (93.7 to 103.3 ) & 0.52 & 127.1 (116.2 to 138.1$)$ & 100.0 (94.7 to 105.4$)$ & 0.001 \\
\hline BMI $\left(\mathrm{kg} / \mathrm{m}^{2}\right)$ & $16.1(14.9$ to 17.3$)$ & 15.7 (14.8 to 16.5$)$ & 0.63 & 23.7 (21.5 to 25.8$)$ & 19.1 (18.0 to 20.1$)$ & 0.01 \\
\hline Waist-hip ratio & $0.87(0.83$ to 0.90$)$ & $0.84(0.81$ to 0.86$)$ & 0.09 & $0.81(0.78$ to 0.84$)$ & $0.74(0.72$ to 0.76$)$ & 0.001 \\
\hline Body fat mass (\%) & 20.3 (18.9 to 21.7$)$ & 20.0 (18.2 to 21.9$)$ & 0.62 & 26.6 (24.4 to 28.8$)$ & 21.3 (19.4 to 23.2$)$ & 0.002 \\
\hline
\end{tabular}

SDS = standard deviation score

hair before 9.0 years. Testicular lengths and widths were measured manually in millimetres three times at the time of clinical evaluation and the mean was calculated. Testicular volume was calculated according to Hansen and With $\left[0.52 \times\right.$ length $(\mathrm{cm}) \times$ width $\left.^{2}(\mathrm{~cm})\right] .^{17}$ The mean value for both testicles was used, but in the case of anorchia or an undescended testis the volume of the only measurable testis was

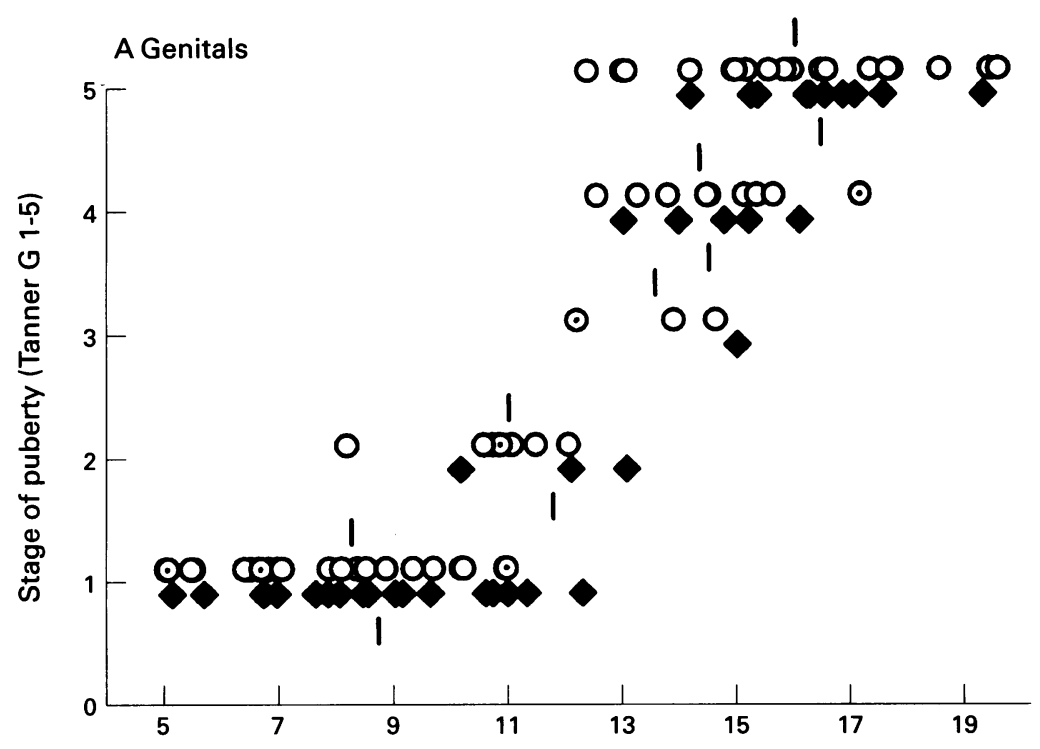

B Pubic hair

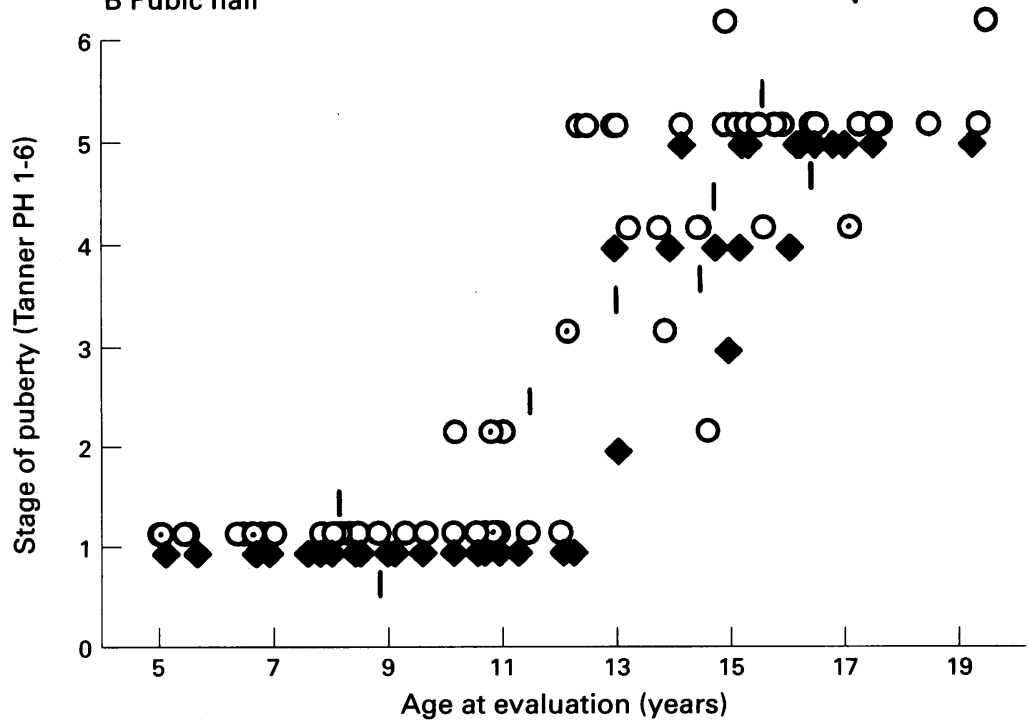

Figure 1 Stage of puberty in the males according to Tanner and Whitehouse: $(A)$ genitals (G 1-5) and (B) pubic hair (PH 1-6) in relation to chronological age: $O=$ patients and $\odot=$ patients with spina bifida, $\bullet=$ controls, $\mid=$ mean ages of patients and controls at each pubertal stage. used. The relative testicular volume was assessed according to Zachmann et al and expressed in standard deviation score (SDS). ${ }^{18}$ Information on the age at menarche and the first day of the last period for the patients and controls was collected using a questionnaire. Data on the age of the mothers at menarche was collected by means of a questionnaire. Bone age was evaluated from an $x$ ray of the left hand and wrist by the method of Greulich and Pyle. ${ }^{19}$ Six patients and five controls had reached adult bone age.

A blood sample was taken in the morning after fasting for a minimum of 10 hours. Basal serum FSH and $\mathrm{LH}$ concentrations were analysed with time resolved fluoroimmunoassays using commercial reagents from Wallac (Turku, Finland). Serum testosterone and oestradiol-17 $\beta$ concentrations were quantified radioimmunologically using commercial reagents from Farmos Diagnostica (Orion Corporation Farmos, Oulunsalo, Finland). Serum sex hormone binding globulin (SHBG) concentrations were also measured with a commercially available time resolved fluoroimmunoassay (Wallac). Free androgen index (FAI) was calculated from the formula $\mathrm{FAI}=100 \times$ serum testosterone $(\mathrm{nmol} / \mathrm{l}) /$ serum SHBG (nmol/l).

The slit ventricle syndrome (SLVS) was considered to be present when a patient had paroxysmal activity in electroencephalograph ${ }^{9}$ and clinical symptoms in addition to slit-like ventricles in computer tomography or magnetic resonance imaging.

STATISTICS

The results were analysed statistically by (a) cross tabulation and $\chi^{2}$ statistics; (b) Student's $t$ test in case of a normal distribution; and (c) the Mann-Whitney $U$ test in the case of a skewed distribution or ordinal variables. The relation between the number of shunt revisions and signs of early puberty was evaluated with the Spearman non-parametric correlation analysis $\left(r_{s}\right)$. The Mantel-Haenszel $\chi^{2}$ for trends was used when comparing the distribution of specific age groups by stage of puberty. The results are expressed as means $(95 \%$ confidence intervals) unless otherwise indicated.

\section{Results}

Both the male and female prepubertal patients had reduced relative height (tables 1 and 2), whereas there was no significant difference in weight or relative weight between them and 
Table 3 Mean age at menarche in hydrocephalic girls with and without spina bifida and in their mothers, compared with the control girls and their mothers; values are mean (95\% confidence interval).

\begin{tabular}{|c|c|c|c|c|c|}
\hline & \multirow{2}{*}{$\begin{array}{l}\text { I. Hydrocephalic girls } \\
\text { without spina bifida } \\
(n=16)\end{array}$} & \multirow{2}{*}{$\begin{array}{l}\text { II. Hydrocephalic } \\
\text { girls with spina } \\
\text { bifida }(n=7)\end{array}$} & \multirow{2}{*}{$\begin{array}{l}\text { III. Control girls } \\
(n=14)\end{array}$} & \multicolumn{2}{|l|}{ pValue } \\
\hline & & & & $I v I I I$ & $I I v I I I$ \\
\hline Mean age at menarche (years) & $11.9(11.2$ to 12.6$)$ & $11.1(10.0$ to 12.2$)$ & $13.2(12.6$ to 13.8$)$ & 0.008 & 0.002 \\
\hline Maternal mean age at menarche (years) & $13.1(12.1$ to 14.0$)$ & $13.6(12.4$ to 14.8$)$ & $12.6(11.9$ to 13.4$)$ & 0.45 & 0.14 \\
\hline p Value & 0.01 & 0.02 & 0.12 & & \\
\hline
\end{tabular}

their controls, except that the male prepubertal patients had an increased waist-hip ratio. The pubertal patients were shorter than their controls, had an increased relative weight, especially the females, and an increased waisthip ratio and body fat mass. The pubertal female patients had also a higher BMI than the control girls.

Gonadal development occurred on an average earlier in the hydrocephalic males than in the controls (Tanner G2-5), the same trend being seen for pubic hair (Tanner PH2-6) (fig 1). In the age group from 12 to 14 years two thirds of the
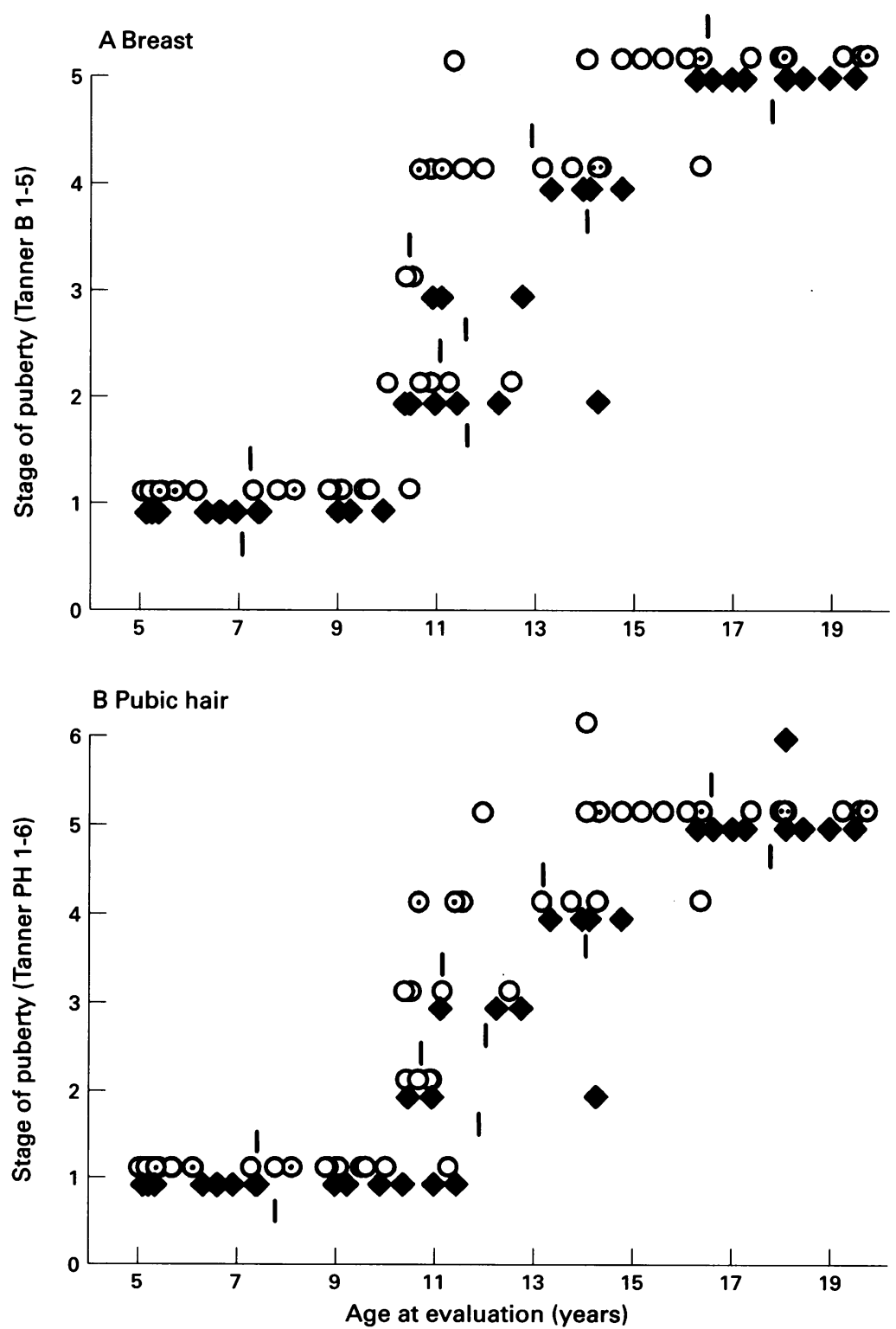

Figure 2 Stage of puberty in the females according to Tanner and Whitehouse: $(A)$ breast $(B$ 1-5) and (B) pubic hair (PH 1-6) in relation to chronological age. $\bigcirc=$ patients and $\odot=$ patients with spina bifida, $\diamond=$ controls, | =mean ages of patients and controls at each pubertal stage. male patients had reached stage 4 or 5 in gonadal development, while only one quarter of the controls had reached the same stages $(p=0.04)$. A similar difference was seen for pubic hair, with two thirds of the male patients aged 12-14 years being at stage 4 or 5 , whereas the correspondingly proportion among the controls was one quarter $(\mathrm{p}=0.05)$. Breast development occurred in general earlier in the hydrocephalic females than in their controls and was accelerated at all stages (Tanner B2-5). A similar trend was seen for pubic hair (Tanner PH2-6) (fig 2). Two thirds of the female patients in the age group from 11 to 13 were at stage 4 or 5 for breast development, whereas none of the controls had reached those stages $(p=0.09)$. Among the females half of the patients 13-15 years of age but none of the controls had reached stage 5 or 6 for pubic hair $(p=0.05)$. Among the patients with spina bifida, pubertal development had occurred earlier than in the controls in the case of the females but not the males (data not shown).

The mean age at menarche was significantly lower in the female patients $(n=23)$ than in their controls $(n=14)$ (11.7 years (11.1 to 12.2) $v 13.2$ years (12.6 to 13.8$) ; \mathrm{p}<0.001$ ) (table 3 ). The age of the patients at menarche was also significantly lower than that of their mothers at that stage (11.7 years $v 13.2$ years; $\mathrm{p}<0.001$ ), while there was no such difference in the control families (13.2 years $v 12.6$ years; $\mathrm{p}=0.12$ ).

The relative testicular volume was significantly greater in the male patients than in the controls (1.2 SDS (0.7 to 1.6$) v 0.2 \operatorname{SDS}(-0.2$ to 0.5$) ; \mathrm{p}<0.001)$, especially among the pubertal patients (1.3 SDS (0.7 to 1.8$) v 0.1$ SDS $(-0.4$ to 0.6$) ; \mathrm{p}<0.01)$. The proportion of patients with a relative testicular volume of more than 2 SDS was higher than that in the controls $(17 / 62 v 3 / 38 ; \mathrm{p}<0.05)$, and relative testicular volume was increased both in the males with spina bifida (1.1 SDS (-1.0 to 3.2) $v 0.2 \operatorname{SDS}(-0.2$ to 0.5$) ; \mathrm{p}=0.16)$ and in those without (1.2 SDS (0.7 to 1.6) $v 0.2$ SDS ( -0.2 to 0.5$) ; \mathrm{p}<0.001)$, although the difference between the patients with spina bifida and the controls was not significant, probably because of the small number of spina bifida patients $(n=6)$.

In the male patients there was a significant correlation between the number of shunt revisions and the relative testicular volume $\left(r_{s}=0.34 ; \mathrm{p}<0.008\right)$. The relative testicular volume was significantly larger among the pubertal male patients, who had had shunt revisions for reasons associated with increased intracranial pressure $(n=26)$ compared to those with no such revisions $(n=10)$ (1.7 SDS 
Table 4 Serum gonadotropin, testosterone, oestradiol, and SHBG concentrations and FAI in prepubertal patients with hydocephalus and their controls; values are mean ( $95 \%$ confidence interval)

\begin{tabular}{|c|c|c|c|c|c|c|}
\hline \multirow[b]{3}{*}{$\mathrm{FSH}(\mathrm{U} / \mathrm{l})$} & \multicolumn{3}{|l|}{ Males } & \multicolumn{3}{|l|}{ Females } \\
\hline & Patients ( $n=26)$ & Controls $(n=19)$ & \multirow{2}{*}{$\frac{p}{0.44}$} & Patients ( $n=18$ ) & Controls ( $n=13$ ) & \multirow{2}{*}{$\frac{p}{0.05}$} \\
\hline & $0.85(0.53$ to 1.17$)$ & 0.72 (0.57 to 0.86$)$ & & 1.57 (1.15 to 1.99$)$ & 1.03 (0.69 to 1.37$)$ & \\
\hline LH (U/l) & 0.14 (0.10 to 0.18$)$ & $0.08(0.05$ to 0.10$)$ & 0.01 & $0.11 \quad(0.10$ to 0.13$)$ & $0.08 \quad(0.05$ to 0.10$)$ & 0.02 \\
\hline Testosterone (nmol/l) & 0.43 (0.28 to 0.59$)$ & 0.49 (0.34 to 0.64$)$ & 0.25 & 0.54 (0.40 to 0.69$)$ & 0.45 (0.31 to 0.58$)$ & 0.31 \\
\hline Oestradiol $(\mathrm{nmol} / \mathrm{l})$ & $0.040(0.03$ to 0.05$)$ & $0.036(0.03$ to 0.04$)$ & 0.11 & $0.044(0.04$ to 0.05$)$ & $0.039(0.03$ to 0.05$)$ & 0.22 \\
\hline SHBG $(\mathrm{nmol} / \mathrm{l})$ & $134.9 \quad(115.2$ to 154.6$)$ & $115.2 \quad(99.8$ to 130.5$)$ & 0.15 & $130.1 \quad(108.2$ to 152.1$)$ & $100.3(80.3$ to 120.2$)$ & 0.04 \\
\hline FAI & $0.52(0.12$ to 0.92$)$ & 0.49 (0.33 to 0.66$)$ & 0.14 & $0.49(0.33$ to 0.65$)$ & 0.49 (0.32 to 0.66$)$ & 0.72 \\
\hline
\end{tabular}

Table 5 Serum gonadotropin, testosterone, oestradiol, and SHBG concentrations and FAI in pubertal and postpubertal patients with hydocephalus and their controls; values are mean ( $95 \%$ confidence interval)

\begin{tabular}{|c|c|c|c|c|c|c|}
\hline & \multicolumn{3}{|l|}{ Males } & \multicolumn{3}{|l|}{ Females } \\
\hline & Patients ( $n=36)$ & Controls $(n=19)$ & $p$ & Patients ( $n=34)$ & Controls $(n=22)$ & $p$ \\
\hline FSH (U/l) & 3.73 (2.97 to 4.48$)$ & $3.14(2.35$ to 3.92$)$ & 0.23 & 4.25 (3.45 to 5.05$)$ & $2.61(1.90$ to 3.33$)$ & 0.005 \\
\hline LH (U/l) & $2.83(2.29$ to 3.38$)$ & $2.65(1.96$ to 3.35$)$ & 0.74 & $3.90(2.60$ to 5.21$)$ & $2.85(1.34$ to 4.36$)$ & 0.12 \\
\hline Testosterone $(\mathrm{nmol} / \mathrm{l})$ & 15.9 (12.7 to 19.1$)$ & 16.1 (10.4 to 21.8$)$ & 0.94 & 1.9 (1.5 to 2.3$)$ & 1.5 (1.2 to 1.8$)$ & 0.26 \\
\hline Oestradiol $(\mathrm{nmol} / \mathrm{l})$ & $0.06(0.05$ to 0.07$)$ & $0.08(0.06$ to 0.10$)$ & 0.08 & $0.21(0.15$ to 0.27$)$ & $0.23(0.14$ to 0.31$)$ & 0.73 \\
\hline SHBG $(\mathrm{nmol} / \mathrm{l})$ & 41.8 (33.6 to 50.0$)$ & 44.5 (35.4 to 53.6$)$ & 0.44 & 61.3 (45.1 to 77.6$)$ & 77.8 (50.9 to 104.6$)$ & 0.06 \\
\hline FAI & 48.0 (36.9 to 59.2$)$ & 45.2 (28.4 to 62.0$)$ & 0.56 & 4.8 (3.0 to 6.6$)$ & 2.3 (1.8 to 2.9$)$ & 0.095 \\
\hline
\end{tabular}

(1.3 to 2.1$) v 1.1$ SDS (0.9 to 1.3$), \mathrm{p}=0.04)$. In the female patients there were no significant relation between the number of shunt revisions and age at menarche.

Only two male patients $(3.2 \% ; 2 / 62)$ were found with a unilateral undescended testis, one of whom was a 6 year old boy with meningomyelocele, who had congenital anorchia on the other side. Another 5 year old boy with meningomyelocele also had unilateral anorchia. Thus the prevalence of congenital anorchia among the males with meningomyelocele was $33.3 \%$ $(2 / 6)$. A third male patient had a unilaterally hypoplastic testis. None of the control boys $(n=38)$ had undescended testes or anorchia. Two hydrocephalic boys who had been shunted at under 1 year of age (aged 10.8 and 15.9 years at the final evaluation) had communicating hydrocele diagnosed for the first time at this clinical examination and subsequently treated surgically. Both of them had a ventriculoperitoneal shunt.

The prepubertal girls with hydrocephalus had significantly higher basal $\mathrm{FSH}, \mathrm{LH}$, and SHBG concentrations than the control girls (table 4), while the prepubertal boys had significantly higher LH concentrations than the control boys but no other statistically significant differences in endocrine variables.

Basal FSH in pubertal and postpubertal hydrocephalic girls was significantly higher than in control girls (table 5). The female patients had increased FSH concentrations, especially in the postovulatory phase of their menstrual period (5.2 U/1 (2.3 to 8.2) $v 1.5 \mathrm{U} / 1$ $(0.9$ to 2.0$)$ in the controls; $p=0.02)$, whereas the difference in the $\mathrm{LH}$ concentrations between the two groups was not significant (4.3 U/1 (1.9 to 6.6$)$ v $2.9 \mathrm{U} / 1$ (-0.9 to 6.8$)$; $\mathrm{p}=0.08)$. SHBG concentrations tended to be lower in the pubertal and postpubertal girls with hydrocephalus than in the controls, while the FAI tended to be higher. There were no differences in oestradiol or testosterone concentrations between the patients and controls, nor were there any statistically significant differences in gonadotrophin, sex hormone, or SHBG concentrations between the pubertal and postpubertal boys with hydrocephalus and their controls.

Based on retrospective data there were five patients with true precocious puberty in this population (table 6), giving a frequency of $4.4 \%(5 / 114)$. Two of these were boys.

\section{Discussion}

The relation between pubertal development and chronological age has been evaluated previously in hydrocephalic patients with meningomyelocele, ${ }^{6}$ but not in subjects with hydrocephalus of other aetiologies. We observed in this cross sectional study that pubic hair developed significantly earlier in the hydrocephalic patients than in the controls and that genital development in the males also occurred significantly earlier.

Table 6 Patients with precocious puberty

\begin{tabular}{|c|c|c|c|c|c|c|c|c|c|c|c|c|}
\hline \multirow[b]{2}{*}{ Case No } & \multirow[b]{2}{*}{ Sex } & \multirow[b]{2}{*}{$\begin{array}{l}\text { Age at } \\
\text { first } \\
\text { operation } \\
\text { (years) }\end{array}$} & \multirow{2}{*}{$\begin{array}{l}\text { First } \\
\text { reported } \\
\text { sign of } \\
\text { puberty }\end{array}$} & \multirow{2}{*}{$\begin{array}{l}\text { Age at } \\
\text { first sign } \\
\text { of puberty } \\
\text { (years) }\end{array}$} & \multicolumn{4}{|c|}{ At final evaluation } & \multirow[b]{2}{*}{$\begin{array}{l}\text { Age at } \\
\text { menarche } \\
\text { (years) }\end{array}$} & \multirow[b]{2}{*}{ Revisions } & \multirow[b]{2}{*}{$S L V S$} & \multirow[b]{2}{*}{ Aetiology } \\
\hline & & & & & $\begin{array}{l}\text { Age } \\
\text { (years) }\end{array}$ & $\begin{array}{l}\text { Bone age } \\
\text { (years) }\end{array}$ & $\begin{array}{l}\text { Relative } \\
\text { height } \\
\text { (SDS) }\end{array}$ & $\begin{array}{l}\text { Stage of } \\
\text { puberty }\end{array}$ & & & & \\
\hline 1 & $\mathbf{F}$ & 0.03 & Menarche & 8.7 & 18.1 & 18.0 & -5.0 & В5PH5 & 8.7 & 6 & Yes & Meningomyelocele \\
\hline 2 & $\mathrm{~F}$ & 3.2 & B2-3 & 7.9 & 13.9 & 16.0 & -0.7 & B4PH4 & 9.0 & 1 & No & $\begin{array}{l}\text { Cysta of foramen } \\
\text { Monro }\end{array}$ \\
\hline 3 & $\mathrm{~F}$ & 0.2 & $\mathrm{PH} 2$ & 8.7 & 19.4 & Adult & -2.5 & B5PH5 & 10.7 & 9 & Yes & Porencephaly \\
\hline 4 & $\mathbf{M}$ & 2.6 & G3 & 8.8 & 13.0 & 17.0 & 3.8 & G5PH5 & & 8 & No & Aqueductal stenosis \\
\hline 5 & $\mathbf{M}$ & 0.2 & G3PH3 & 10.1 & 14.3 & 17.0 & 1.3 & G5PH5 & & 12 & Yes & $\begin{array}{l}\text { Purulent meningitis, } \\
\text { aqueduct stenosis }\end{array}$ \\
\hline
\end{tabular}


The age at menarche varied from 9.4 to 11.9 years in the girls with meningomyelocele examined by Greene et $a l,{ }^{6}$ but the number of menstruating girls in that series was smallonly four. Dalton and Dalton studied the mean age at menarche in 37 girls with neural tube defects $^{20}$ and obtained a figure of 10.5 years, but there is no information on how many of these girls had hydrocephalus as well. The other groups of girls included were ones with asthma, cerebral palsy, epilepsy, retinoblastoma, and other chronic diseases, and their mean ages at menarche varied from 10.8 to 13.5 years. Thus it was the girls with neural tube defects who had the youngest mean age at menarche in that survey.

The mean age at menarche among Finnish girls in general in 1982 was 13.3 years, while that of their mothers had been 13.6 years. ${ }^{21}$ There has been a secular trend towards an earlier menarche over the past century, with a decrease of about 3-4 months per decade, and the average age at menarche in the United Kingdom, for example, is currently 12.8 years. ${ }^{22}$ The present hydrocephalic girls, however, experienced their menarche an average of 1.5 years earlier than the control girls and 1.5 years earlier than their mothers, confirming that factors other than genetic ones are responsible for the earlier manifestation of the menarche in girls with hydrocephalus.

What factors determine the age at menarche? Numerous phenomena act in combination, including genetic influences, socioeconomic conditions, general health and wellbeing, nutritional status, and regular, intensive physical exercise, since athletics, gymnastics, and ballet, for instance, have been associated with delayed maturation and menarcheal age. ${ }^{22}$ The genetic impact does not seem to be crucial in the present series, and the same general health and wellbeing may be said to apply to both the patients and the controls. Likewise, there were no subjects in either group who took part in competitive sports. In terms of nutritional status, the pubertal hydrocephalic girls had a significantly greater relative weight than the control girls. ${ }^{23}$ Adipose tissue is an important source of oestrogen, and its amount has an influence on oestrogen metabolism. There is a hypothesis concerning a threshold weight for height and a critical proportion of body fat required before the menarche can occur. ${ }^{22} \mathrm{~A}$ change in body composition is known to occur during the adolescent growth spurt, so that the ratio of lean body weight to fat is on an average $5: 1$ at the initiation of the growth spurt and decreases to $3: 1$ before the menarche, when about $22 \%$ of the body weight is fat. We calculated the ratio of lean body weight to fat in the prepubertal hydrocephalic girls relative to that in the controls and could not detect any differences in this or in age, weight, or relative weight, whereas the pubertal and postpubertal hydrocephalic girls had a higher absolute and relative weight ${ }^{23}$ and their lean body weight ratio to fat was lower, although their mean age did not differ from that of the control girls. Overweight becomes more severe later in puberty, however, and accordingly it can hardly explain the younger age at menarche alone.

Previous reports on pubertal development in patients with hydrocephalus concern mainly girls, but the present series also included boys and compared them with age matched controls, upon which the patients were found to have significantly larger relative testicular volumes. The number of male patients with anorchia, hypoplastic testis, cryptorchidism, and communicating hydrocele indicates that the genitalia of boys with hydrocephalus should be examined initially at diagnosis and subsequently at regular intervals, especially in cases with ventriculoperitoneal shunts.

An increase in pulsatile $\mathrm{LH}$ secretion plays a crucial role in the induction of puberty, and circulating $\mathrm{LH}$ concentrations are a sensitive indicator of pubertal development. ${ }^{24}$ The emergence of regular daytime $\mathrm{LH}$ pulses is closely related to the onset of breast development in girls ${ }^{25}$ and there is also an increase in LH pulse frequency associated with the initiation of puberty in boys. ${ }^{25}$ The present prepubertal children with hydrocephalus were found to have higher basal gonadotropin concentrations, particularly LH levels, than the controls, indicating a central stimulus before any clinical sign of puberty can be detected. Pubertal female patients had increased FSH concentrations, especially in the postovulatory period. Neely et al have shown in a recent study ${ }^{27}$ that spontaneous serum gonadotropin concentrations are more specific for the evaluation of precocious puberty than stimulated $\mathrm{LH}$ and FSH concentrations.

Gonadotropin releasing hormone ( $\mathrm{GnRH}$ ) is secreted mainly from the medial basal hypothalamus in episodic bursts into the hypothalamic-pituitary portal system and thereby to the anterior pituitary. The variation in the frequency of its pulsatile secretion affects the amount of LH and FSH released. The postnatal decrease in gonadotropin secretion during childhood before the onset of puberty, the juvenile pause, appears to be mediated by the central nervous system (CNS). Damage to the CNS may release the inhibition and bring about premature pubertal development. ${ }^{28}$

The reasons for the increased gonadotropin secretion in the prepubertal patients with hydrocephalus remain to be defined, but one can assume that it may be due to increased intracranial pressure or unphysiological variations in this pressure. There was a significant correlation between the number of shunt revisions and relative testicular volume in hydrocephalic males. The relative testicular volume was also larger in those prepubertal male patients who had shunt revisions associated with increased intracranial pressure, and the enlargement of the testes is the first sign of puberty in males.

Although SHBG concentrations were higher in the prepubertal patients with hydrocephalus than in the controls, the present data do not provide information on whether this is a primary phenomenon or secondary to enhanced gonadotropin secretion. In the latter case they would reflect an attempt to counter- 
act the effects of increased peripheral gonadotropin concentrations by reducing the circulating concentrations of free sex hormones. ${ }^{29}$ If primary, the high SHBG in combination with decreased free sex hormone concentrations may stimulate pituitary gonadotropin release and by that mechanism contribute to the induction of early puberty. Accelerated sexual maturation would then result in decreased concentrations of SHBG in pubertal subjects with hydrocephalus. Another factor contributing to low SHBG in such subjects is the increased frequency of obesity among them. ${ }^{23}$

The prevalence of precocious puberty observed here was of the same magnitude as in previous reports. ${ }^{1-5}$ In addition, several patients were identified with early puberty that did not fulfil the criteria of true precocious puberty.

The results show that patients with hydrocephalus experience early puberty, which is reflected in an early menarche in girls and an increased testicular volume in boys. This accelerated physical maturation does not seem to be due to genetic factors. Based on our observations, one can speculate that the increased gonadotropin concentrations observed especially in prepubertal patients may be a consequence of unphysiological increases or decreases $^{30}$ in intracranial pressure.

This work was supported by the Sigrid Jusélius Foundation, Helsinki, Finland (TL,MK), the Alma and $\mathrm{K}$ A Snellman Foundation, Oulu, Finland (TL), the Arvo and Lea Ylppö Foundation, Helsinki, Finland (TL), and the Foundation for Paediatric Research in Finland (TL)

1 Capotal R, Segrestaa M, Dorf G. Endocrine expression of hydrocephalus. A case of primary amenorrhoea revealing a stenosis of foramen of Magendie. Acta Endocrinol 1983; 102:161-6.

2 Moeslein S, Dericks-Tan JSE, Lorenz R, Taubert H-D. Double-stimulation. with LH-RH in primary amenorrhea caused by chronic internal hydrocephalus: a case study. Gynecol Endocrinol 1987;1:201-7.

3 TomonoY, MakiY, Ito M, NakadaY. Precocious puberty due to postmeningitic hydrocephalus. Brain Dev 1983; 5:414-7.

4 Kaiser G, Ruedeberg A, Arnold M. Endocrinological disorders in shunted hydrocephalus. $Z$ Kinderchir 1989; 44(suppl 1):16-17.

5 Mayer S, Landau H. Precocious puberty in myelomeningocele patients. F Pediatr Orthop 1984;4:28-31.

6 Greene SA, Frank M, Zachmann M, Prader A. Growth and sexual development in children with meningomyelocele. sexual development in childre

7 Amacher AL, Wellington J. Infantile hydrocephalus: longterm results of surgical therapy. Child's Brain 1984; 11:217-29.
8 Serlo W. Shunt treatment of hydrocephalus in children [dissertation]. Acta Universitatis Ouluensis 1985; Series D, Medica 130.

9 Saukkonen A-L. Childhood hydrocephalus. Electroencephalography, epilepsy and slit ventricle syndrome [dissertation]. Acta Universitatis Ouluensis 1989; Series D, Medica 185.

10 Pääkkö E, Löppönen T, Saukkonen A-L, et al. Information value of magnetic resonance imaging in shunted hydrocephalus. Arch Dis Child 1994;70:530-5.

11 Sorva R, Perheentupa J, Tolppanen EM. New format for a growth chart. Acta Paediatr Scan 1984;73:527-9.

12 Mueller WH, Marbella A, Harrist RB, et al. Body circumferences as alternatives to skinfold measures of body fat disences as alternatives to skinfold measures of body fat
tribution in children Ann Hum Biol 1989;16:495-506

13 Owen GM. Measurement, recording and assessment of skinfold thickness in chilhood and adolescence: report of a small meeting. Am $\mathcal{f}$ Clin Nutr 1982;35:629-8.

14 Parizkova J. Total body fat and skinfold thickness in children. Metabolism 1961;10:794-807.

15 Keys A, Brozek J. Body fat in adult man. Physiol Rev 1953; 33:245-325.

16 Tanner JM, Whitehouse RH. Clinical longitudinal standards for height, weight, height velocity, and stages of puberty. Arch Dis Child 1976;51:170-82.

17 Hansen PF, With TK. Clinical measurements of testes in boys and men. Acta Med Scand 1952; suppl 266:457-65.

18 Zachmann M, Prader A, Kind HP, Häfliger H, Budliger $H$. Testicular volume during adolescence: cross-sectional and Testicular volume during adolescence: cross-sectional and
longitudinal studies. Helv Paediatr Acta 1974;29:61-72.

19 Greulich WW, Pyle SI. Radiographic atlas of skeletal development of the hand and wrist. Stanford: California: Stanford University Press, 1959.

20 Dalton ME, Dalton K. Menarcheal age in the disabled. $B M \mathcal{F}$ 1978;ii:475.

21 Ojajärvi P. The adolescent Finnish child. A longitudinal study of anthopometry, physical development and physiological changes during puberty (in Finnish) [dissertation]. University of Helsinki, 1982.

22 Rees M. Menarche when and why? Lancet 1993; 342:1375-6.

23 Löppönen T, Saukkonen A-L, Serlo W, Lanning P, Knip M. Slow prepubertal linear growth but early pubertal growth spurt in patients with shunted hydrocephalus. Pediatrics 1995;95:917-23.

24 Apter D, Cacciatore B, Alfthan H, Stenman U-H. Serum luteinizing hormone concentrations increase 100 -fold in females from 7 years of age to adulthood, as measured by time-resolved immunofluorometric assay. $\mathcal{F}$ Clin Endocrinol Metab 1989;68:53-7.

25 Apter D, Butzow TL, Laughlin GA, Yen SSC. Gonadotropin-releasing hormone pulse generator activity during pubertal transition in girls: pulsatile and diurnal patterns of circulating gonadotropins. $f$ Clin Endocrinol Matterns 1993;76:940-9.

26 Dunkel L, Alfthan H, Stenman U-H, Tapanainen P, Perheentupa J. Pulsatile secretion of $\mathrm{LH}$ and FSH in prepubertal and early pubertal boys revealed by ultrasensitive time-resolved immunofluorometric assays. Pediatr Res 1990;27:215-21.

27 Neely EK, Wilson DM, Lee PA, Stene M, Hintz RL. Spontaneous serum gonadotropin concentrations in the evaluation of precocious puberty: $\mathcal{F}$ Pediatr 1995;127:47-52.

28 Styne DM. The physiology of puberty. In: Brook CG, ed. Clinical paediatric endocrinology. 3rd Ed. Cambridge: Blackwell Science, 1995:234-52.

29 Root AW, Rogol AD. Organization and function of the endocrine system. In: Kappy MS, Blizzard RM, Migeon endocrine system. In: Kappy MS, Blizzard RM, Migeon CJ, eds. The diagnosis and treatment of endocrine disorders in Publisher, 1994:30-1.

30 Serlo W, Heikkinen E, Saukkonen A-L, Wendt LV. The incidence and management of the slit ventricle syndrome. Acta Neurochir (Wien) 1989;99:113-6. 